\title{
Contact Point Headache in Adolescence: Diagnostic and Therapeutic Challenges
}

\author{
Novak Vukoje ${ }^{1 *}$, Milica Kovacevic Chicago ${ }^{2}$, and John Garito ${ }^{3}$ \\ ${ }^{1}$ ENT office "dr Vukoje" Petrovaradin, Serbia \\ ${ }^{2}$ Chicago, IL, USA \\ ${ }^{3} \mathrm{PhD}$, Inventer the dual Frequency device and the RF electrodes, USA
}

Submission: February 17, 2020; Published: March 05, 2020

*Corresponding author: Milica Kovacevic MD Chicago, IL, USA

Keywords: Contact Point Headache; Septoplasty, Conchoplasty; Endonasal Blockage of the Anterior Ethmoidal Nerve

\section{Introduction}

One of the unusually rare headaches, known as contact point headache, is a new type of headache in the International Classification of Headaches, which is a major therapeutic challenge in addition to diagnosis. This is also one of the reasons that patients have wandered for years without diagnosis and adequate treatment. Unfortunately, chronic headache pain in the school-age population, especially in adolescence and teenagers, is not uncommon. Although the etiological factors are quite different, rhinogenic headaches, especially touch point headaches, are increasingly more common. It was recognized and described by Sluder in 1908, by which it was named, but it still does not receive enough attention.

Cephalgia is characterized by attacks of severe, sharp, unbearable and unilateral pain that is most often focused in the area of the lateral wall of the nose and the corner of the eye that belongs to the innervation area of the anterior ethmoidal nerve. It also contributes to the fact that the nerve lies superficially in the mucous membrane of the nose and is subject to various agents that irritate it. It splits into the outer nasal and inner septal branches and is a continuation of the nasociliary nerve, a branch of the optic nerve of the upper branch of the trigeminal nerve. It is responsible for sensory innervation of certain topographic regions of the nasal cavity. There are numerous causes that can lead to irritation of the nerve, most referred to as inflammatory, allergic and tumor etiology.

Mechanical, chemical, or thermal stimulation of the nasal mucosa also causes congestion, hyperemia, and mucosal edema, which causes compression and irritation of the anterior fibers of the anterior ethmoidal nerve, causing pain. Contact between the mucosa of the upper, middle, and lower nasal shells, concha bullosa, ethmoidal sinusitis on the one hand, and the crystalline, spinal or deviation of the nasal septum on the other, are most commonly responsible for this pathology. Due to incomplete diagnosis and inadequate treatment, many patients suffer from pain for years, which disrupts their daily activities and can lead them into a depressed mood.

Patients often change doctors, therapy, resort to selfmedication, seek salvation of a surgeon, etc. Every pain in this region requires specific diagnostics and therapy. It should be noted that the treatment of chronic headache pain is individual and that there is no one approach, method and cure for all patients, nor is the treatment the same for all patients. For this reason, various specialists are engaged in the treatment of cephalgic pain in the following population: pediatricians, Neuropediatrici ans, neurologists, dentists, oral surgeons, neurosurgeons, otolaryngologists, ophthalmologists, etc. CT and MRI head scans can detect the cause of rhino-sinusogenic headaches and detect the point of contact. However, in the cases where only mucosal contact is present with mucosal swelling and headache attacks and the scans are done in the quiet phase "without pain," the findings can be clear and prompt the doctor to attribute the headache, especially in adolescence, to "crazy years". For this reason, it is recommended that additional diagnostics, a lidocaine test, and endoscopic examination of the nose are performed at the stage of the onset of pain.

In the area of the head, the primary pain is most often caused by neuralgia of the fifth cranial nerve / n. tigeminus /, glossopharyngeal nerve, occipital nerves / occipital headache /, while secondary headache is usually associated with rhino- 
sinusogenic etiology. Attacks of pain, headache contact point, can occur 1 to 8 times a day with a duration of 15-180 minutes during the day $[1,2]$. Often, they are associated with conjunctival hyperemia, epiphora, ptosis, miosis, and eyelid edema. The attack is often preceded by colds, nasal obstruction and rhinorrhea. Diagnosis of this headache in children requires a collaboration of multiple medical specialties with numerous diagnostic procedures $[2,3]$.

The guidelines that may be a sign and lead a physician to suspect a "Contact Point Headache" are the following:

a) Patients complain of severe, sudden, radiating unilateral pain, localized periorbital and in projection of the root of the nose and medial eye corner with irradiation to the zygomatic, frontal and temporal region

b) Symptoms include nasal obstruction, unilateral rhinorrhea, post-nasal drip, epiphora and infrequent redness on the pain side.

c) During an ENT examination, the contact points between the mucosa of the curved nasal septum or the pronounced spine of the septum of one side and the mucous membranes of the lateral wall of the nose, the other side, can be observed in these patients.

d) A lidocaine test, to be done at the headache phase, relative to placebo, results in rapid cessation or significant resolution of pain in more than $50 \%$ of cases.

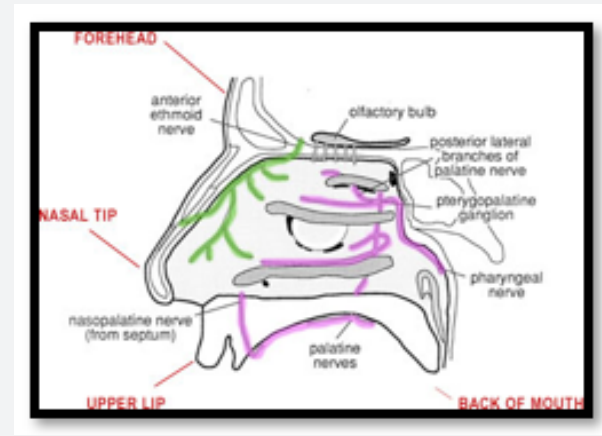

Figure 1: (a) Note infiltration of epithelium and sub epithelium with inflammatory cells. X100; (b) Cyst found in palatal epithelium. X200; (c) Fibrosis in sub epithelium. X100.

Confirmation of the correct diagnosis is given by surgical separation of the touch points, which in most patients eliminates or significantly reduces the headache in the next seven days (Figure 1). The question is why some people, with a pathological finding in the nose and present mucosal contact points, do not have a headache. Therefore, cephalea has emerged now and the "contact point" lasts for years. Also, the enigma is the absence of headache in patients with complete nasal obstruction and pronounced long-term contact between the nasal polyps and the mucous membrane of the septum. How do you explain that contact point headache is three times more common in girls than boys? Unfortunately, there remains some dilemmas in the pathophysiology, diagnosis and therapy of this pain, which medicine has not yet clarified.

It is believed that over time, the nerve that is "squeezed" between the two structures becomes hypersensitive and becomes neuropathic leading to localized pain. The pathophysiology of pain also mentions mediators, neuropeptides, calcitonin, substance $\mathrm{P}$, etc. which are thought to cause vasodilation and edema of the nasal mucosa in addition to the central mechanism, further exacerbating the problems [4-6]. These chemical mediators are more prevalent in individuals with two mucosal contact and can be a driving factor for headache. What is typical of this headache is that the pain usually begins after a cold, a viral infection, or allergic manifestations that cause mucosal edema and thus intensify their contact. Pain can be associated with bilateral conjunctival hyperemia, lacrimation and eyelid swelling.

It is usually localized between the root of the nose and the medial eye corner. By nature, it is sharp, radiant and strong, refractory to analgesics. In addition, temporary and occasional presence of contact points that are compatible with the nasal cycle can be the trigger for this type of headache. Cephalea may be associated with sensitivity to light or noise, so it is usually noted as a migraine without aura. The headache analysis considers the intensity of pain (VAS 1-10), the duration of the headache (number of hours per $24 \mathrm{~h}$ ) and frequency [number of days per month]. Diagnostic procedures performed such as CT, MRI, EEG, etc. are often clear, so they can get a doctor to associate cephalopathy with another etiology.

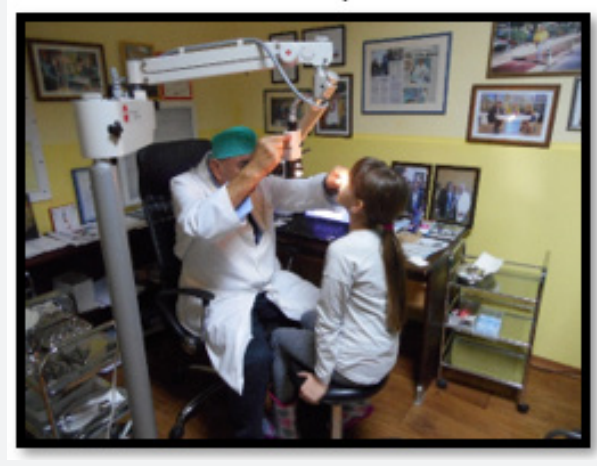

Figure 2: Clinical examination of the nose represents the first diagnostic procedure in the detection of rhizogenic headaches.

Juvenile cephalgia that occurs in adolescents, in the absence of nasal symptoms, is usually observed by a pediatrician or neuro-pediatrician who, after standard diagnostics for this pathology, prescribe medication, which is often unsuccessful. Pharmacotherapy that is effective in eliminating pain is from the group decongestants and local anesthetics. They reduce the 


\section{Global Journal of Otolaryngology}

existing mucosal swelling, preventing mucosal contact, thereby eliminating mechanical pressure on nerve endings. Because their therapeutic effect is limited in time, new nasal mucosal edema causes pain to recur. However, xylocaine blockage of the anterior ethmoidal nerve or splenoplatinum ganglion produces better results and more than half of the patients are satisfied with its effect (Figure 2).
The diagnostic procedure for these headaches includes ENT examination, nasal endoscopy, CT sinus, brain MRI, and a lidocaine test to be done during the acute onset of a headache. A piece of cotton wool soaked in $10 \%$ lidocaine is placed between the touch points in the nose at a time interval of ten minutes and the test is considered positive if the pain is alleviated or reduced by more than $50 \%$ in the next 5-10 minutes (Figure 3).

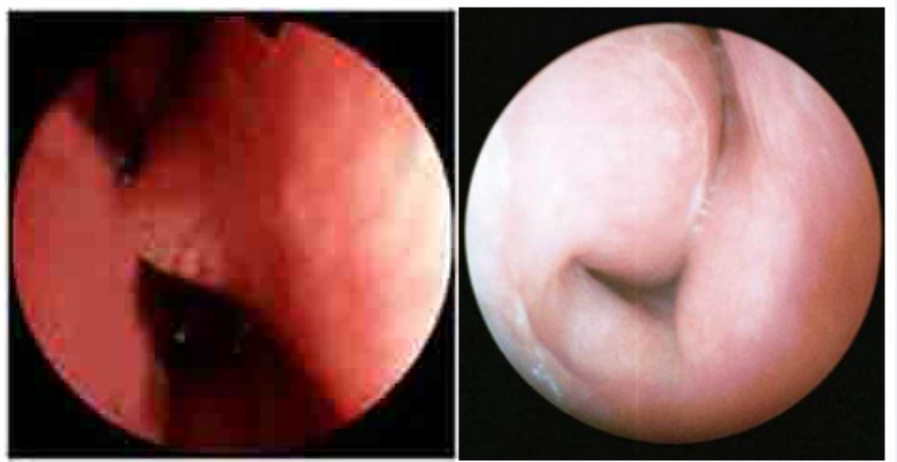

Figure 3: Mucous contact caused by the spine of nasal septum / left / and enlarged lower nasal shell / right / as a cause of headache.

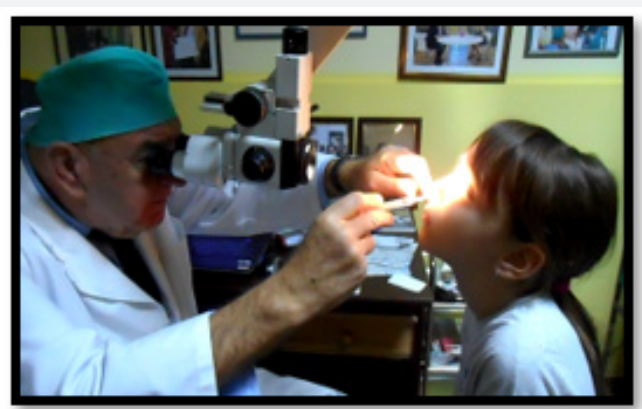

Figure 4: Endonasal blockage of the anterior ethmoidal nerve, using xylocain or lidocaine, soon leads to pain relief. The anesthetic is applied about $5 \mathrm{~mm}$ above the middle nasal shell into the mucosa of the lateral wall of the nose.
The most common site of contact is between the mucosa of the septum and the middle nasal shell [40\%], the septum and the lower nasal shell [10\%], the spine of the nasal septum and the lateral wall of the nose [20\%], and the concha bulosa and septum [20\%]. In about $10 \%$ of cases, the "contact point" occurs at more than one point (Figure 4).

Bearing in mind that headache of contact points is due to compression of the anterior ethmoidal nerve resulting from the contact of the mucous membrane of the lateral wall of the nose and the nasal septum, which is contributed by various pathoanatomical conditions in the nose that can be surgically corrected, surgery remains the most optimal treatment of this pathology (Figure 5).
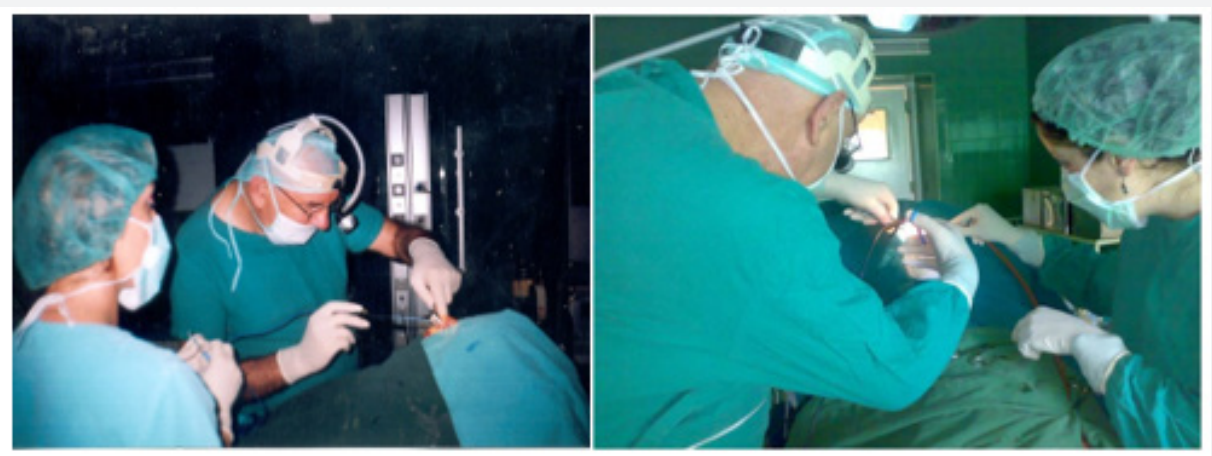

Figure 5: Surgical treatment of contact point headaches. Submucous conchoplasty in progress / right / septoplasty left.

The indications for surgery include:

i. Unilateral headache treated for at least one year without improvement ii. Presence of contact points in the nose verified endoscopically or via CT or NMR examination

iii. Positive lidocaine test. 
The aim of the study was to present our results of contact point headache treatment in 24 patients aged 12 to 18 years.

\section{Material and Methods of Work}

In the period from 2015 to 2018, the author treated 24 children aged 12 to 18 years who had previously undergone all diagnostic procedures related to headache and for whom conservative therapy lasting longer than one year did not give satisfactory results. After analysis of medical records, endoscopic examination of the nose and lidocaine test, treatment was performed in 11 cases with xylocaine blockage of the anterior ethmoidal nerve for 4 sessions, and in 13 cases surgery was performed. Seven patients underwent submucosal conchoplasty with RF waves, two patients had septoplasty, and three septoplastics with turbinoplasty, and one concha bullosa surgery.

The success of the therapy was evaluated the statements of the children and parents regarding the intensity, frequency and duration of the headache, before and 3-6 months after the treatment. The results of the surgical and medicamentous treatment are shown in Chart 1 . Of the nine operations conducted, the headaches completely stopped [69.3\%], in one patient, pain decreased significantly [7.6\%], in three patients, the pain remained the same. Of the 11 patients treated with blockages, six no longer complained of pain [54.5\%] in two [18.1\%] decreased in intensity and frequency, while in three [27.4\%] improvements.

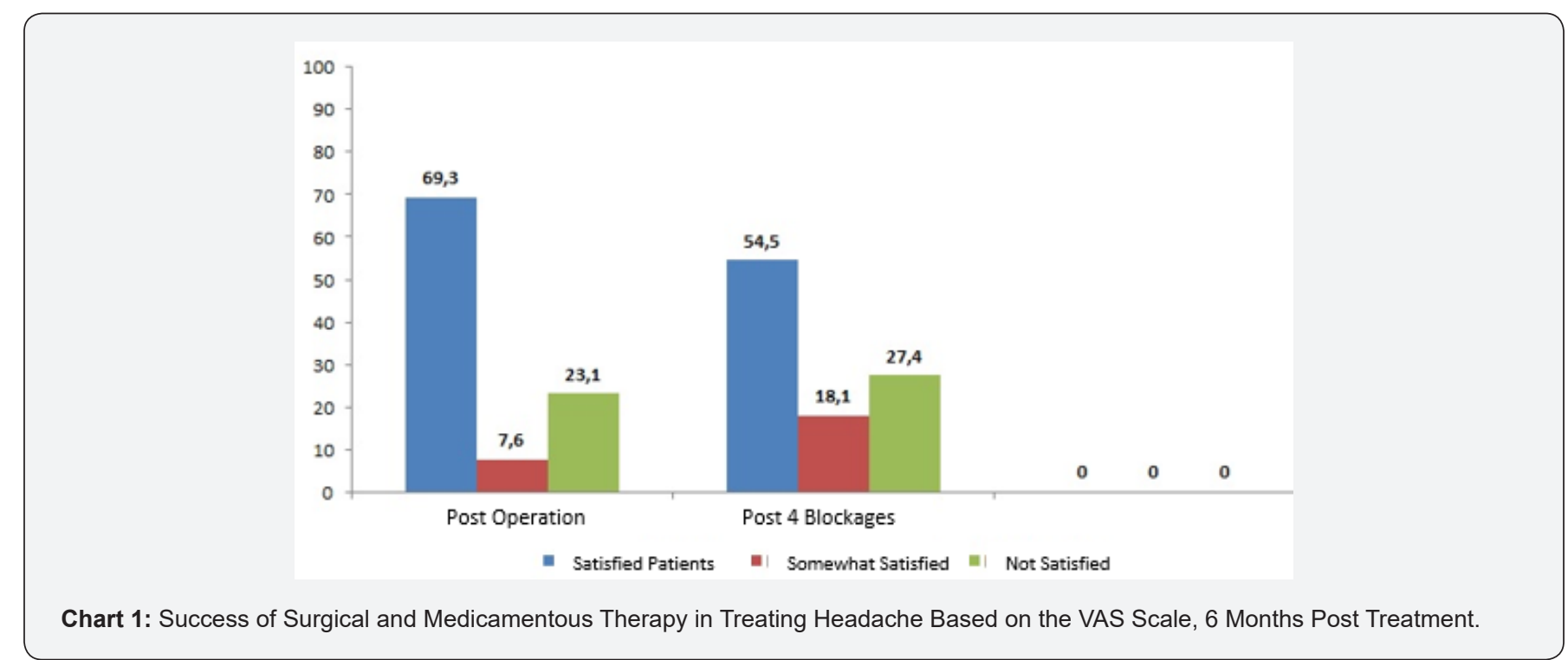

\section{Discussion}

Due to prolonged and often inadequate treatment, many patients suffer from severe pain for years due to the lack of recognition of contact point headache. To relieve their pain, doctors prescribe several analgesics, tricyclic antidepressants, beta-blockers, antiepileptic drugs, narcotics, steroids, muscle relaxants, etc. Although pharmacotherapy is the first, but not always satisfactory option in treating chronic headache, it should be started treatment [5,6,7]. Medicines that may have some positive effects in pain relief are from the group of decongestants and local anesthetics. They lead to a decrease in existing mucosal swelling and thus prevent mucosal contact. Because their effect is limited in time, new mucosal edema causes pain to recur. Given that the cause of contact point headaches is due to compression of the anterior ethmoidal nerve caused by pathoanatomical structures in the nose that can be surgically corrected, it remains that surgical separation of contact points is the most optimal treatment for these patients [1, 2, 7-11].

Surgical treatment of rhizogenic headache usually involves the correction of the nasal septum, removal of the spine of the septum, reduction of enlarged nasal shells, resection of the ethmoidal bulla, or elimination of other anomalies, depending on which deformities lead to mucosal contact. The goal of this surgery is to correct the existing pathology in the nose, restore normal respiration, separate the mucosal point contacts and prevent future mechanical irritation of the anterior ethmoidal nerve.

There are several studies that have analyzed the success of contact point headache surgery. Inclusion criteria and results were different from study to study. The largest series, presented by Huang and colleagues [7], included 66 patients divided into three groups: with nasal septum deviation, concha bullous, and overburdened orbito-ethmoidal Halle cells. Following surgical treatment, the authors found a decrease in the intensity and frequency of headache in $88.8 \%$ of patients. In a retrospective study involving 34 individuals with mucosal contact between the septum and nasal shells, Parsons and Batra [8] reported an improvement of $91 \%$ after surgery.

Peric and colleagues [10] point out success in over $88 \%$ and state that patients do not need any treatment after surgical 
treatment. Sadeghi and colleagues [11] reported similar results [an improvement of $93.3 \%$ of patients] on a similar sample of 30 patients. In one study published by Welge-Luessen and colleagues with headaches caused by contact between the middle nasal shells and the nasal septum, after a 10 -year observation, found that the rate of improvement dropped from $85 \%$ to $65 \%$. This result suggests that the selection criteria for these patients should be better standardized and that the follow-up period after the surgical procedure should cover a longer period. Vukoje [1] reported a $73.3 \%$ success rate of an earlier study, which is generally slightly lower than the results of other authors.

The results, referring to the teenage and adolescent ages in our sample, are even weaker and $69.3 \%$ were satisfied after surgery $[12,13]$. The reason should be sought in the pathology of pain, the age of the patient, the type of surgery, the intensity, frequency and duration of headaches, as well as shorter postoperative follow-up of patients. The location, extent and extent of mucosal contact are often crucial in the range between good and bad results $[1,14,15]$. Sometimes, small surgical interventions will produce great success, and in other cases much larger interventions that achieve adequate expansion of the nasal canals and elimination of mucosal contacts will remain unsatisfactory. This indicates that the pathophysiology of pain in this type of headache has not been fully elucidated and that further studies should be directed toward the molecular level [16].

A less invasive option in the treatment of contact point headache involves the use of neural blockages. Usually a topical anesthetic in the form of lidocaine or xylocain combined with corticosteroids is used and is applied about $5 \mathrm{~mm}$ above the grip of the middle nasal shell to the mucosa of the lateral wall of the nose. The results are variable, but more than $50 \%$ of patients feel significant relief already after the second dose. In our statistics, in over $54 \%$ of cases patients were satisfied with this treatment.

\section{Conclusion}

Contact point headache is still a diagnostic and therapeutic problem today. This is indicated by over $30 \%$ of dissatisfied patients who were not helped by any form of treatment. Surgical removal of the contact points of the nasal mucosa through various endonasal procedures reduces the intensity of the headache. In our causation, surgical treatment resulted in cessation of pain in $69.3 \%$ of cases. This indicates that surgery is a satisfactory option in treating this pathology. Conservative treatment in the form of blockage of the anterior ethmoidal nerve gave a poor result and the headache was significantly reduced or disappeared completely in $54.5 \%$ of the treated patients.

The author considers that, when contact headache is suspected, before surgery, the patient must undergo a complex diagnostic procedure to rule out other causes of headache. In addition, more precise criteria should be developed for the selection of patients planned for surgery or other treatment, which should improve the overall results. Long-term studies should be designed to detect different levels of contact point locations and their role in the etiology of cephalgic pain. In fact, a clear link between contact points and headache in the pediatric population is sometimes difficult to prove. Children with headaches resistant to conservative therapy in addition to the neurologist and neurotherapies should also be examined by an otolaryngologist, who should carefully examine the nose, looking for possible contact points, assuming that they may be a major cause of cephalic disease. Systemic, neurovascular, as well as numerous other possible causes of headache should be ruled out beforehand.

\section{References}

1. Novak Vukoje, John Garito (2018) Surgical Medicamentous Approach to the Treatment of the Contact Point Headache. Global Journal of Otolaryngology 13(4): 555870.

2. Osama, Hossam S Elsherif, Emad M Shehata, Ahmed Younes (2012) Middle Turbinate Evacuation Conchoplasty in Menagment of ContactPoint Rhinogenic Headache in Children. International Journal of Clinic Pediatries 1(4-5): 115-123.

3. Patel ZM, Setzen M, Poetker DM, DelGaudio JM (2014) Evaluation and management of "sinus headache" in the otolaryngology practice. Otolaryngol Clin North Am 47(2): 269-287.

4. Marmura MJ, Silberstein SD (2014) Headaches caused by nasal and paranasal sinus disease. Neurol Clin 32(2): 507-523.

5. Roozbahany NA, Nasri S (2013) Nasal and paranasal sinus anatomical variations in patients with rhinogenic contact point headache. Auris Nasus Larynx 40(2): 177-183.

6. Stammberger H, Wolf G (1988) Headaches and sinus disease: the endoscopic approach. Ann Otol Rhinol Laryngol Suppl 134: 3-23.

7. Huang HH, Lee TJ, Huang CC, Chang PH, Huang SF (2008) Nonsinusitis-related rhinogenous headache: a ten-year experience. Am J Otolaryngol 29(5): 326-332.

8. Parsons DS, Batra PS (1998) Functional endoscopic sinus surgical outcomes for contact point headaches. Laryngoscope 108(5): 696702 .

9. Herzallah IR, Hamed MA, Salem SM, Suurna MV (2015) Mucosal contact points and paranasal sinus pneumatization: Does radiology predict headache causality? Laryngoscope 125(9): 2021-2026.

10. Aleksandar Perić, Dejan Rašić, Uglješa Grgurević (2016) Surgical Treatment of Rhinogenic Contact Point Headache: An Experience from a Tertiary Care Hospital. Int Arch Otorhinolaryngol 20(2): 166-171.

11. Sadeghi M, Saedi B, Ghaderi Y (2013) Endoscopic management of contact point headache in patients resistant to medical treatment. Indian J Otolaryngol Head Neck Surg 65(2): 415-420.

12. Welge-Luessen A, Hauser R, Schmid N, Kappos L, Probst R (2003) Endonasal surgery for contact point headaches: a 10-year longitudinal study. Laryngoscope 113(12): 2151-2156.

13. Peric A, Baletic N, Sotirovic J (2010) A case of an uncommon anatomic variation of the middle turbinate associated with headache. Acta Otorhinolaryngol Ital 30(3): 156-159.

14. Clerico DM, Evan K, Montgomery L, Lanza DC, Grabo D (1997) Endoscopic sinonasal surgery in the management of primary headaches. Rhinology 35(3): 98-101. 
15. Mokbel KM, Abd Elfattah AM, Kamal S (2010) Nasal mucosal contact points with facial pain and/or headache: lidocaine can predict the result of localized endoscopic resection. Eur Arch Otorhinolaryngol 267(10): 1569-1572.

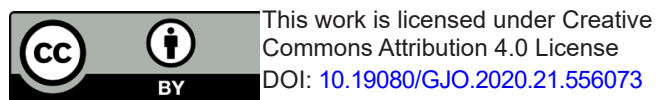

16. Levis D W (2005) The "other" primary headaches in children and adolescents. Pediat Neurol 33: 303-313.

\section{Your next submission with Juniper Publishers will reach you the below assets}

- Quality Editorial service

- Swift Peer Review

- Reprints availability

- E-prints Service

- Manuscript Podcast for convenient understanding

- Global attainment for your research

- Manuscript accessibility in different formats ( Pdf, E-pub, Full Text, Audio)

- Unceasing customer service

Track the below URL for one-step submission https://juniperpublishers.com/online-submission.php 